\title{
Article \\ Composition of Algerian Propolis, Plant Origin, and Its Antiangiogenic Activity In Vitro
}

\author{
Takahiro Hosoya ${ }^{1,2}$, Ikumi Tsuchiya ${ }^{1}$, Toshiro Ohta ${ }^{1}$, Mokhtar Benhanifia ${ }^{3}$ and Shigenori Kumazawa ${ }^{1, *(D)}$ \\ 1 Department of Food and Nutritional Sciences, University of Shizuoka, 52-1 Yada, Suruga-ku, \\ Shizuoka 422-8526, Japan; hosoya@toyo.jp (T.H.); tsuchiya2021@u-shizuoka-ken.ac.jp (I.T.); \\ ohtat@u-shizuoka-ken.ac.jp (T.O.) \\ 2 Department of Nutrition and Health Sciences, Toyo University, 1-1-1, Izumino, Itakura-machi, Ora-gun, \\ Gunma 374-0193, Japan \\ 3 Department of Agricultural Science, Faculty of Natural and Life Sciences, University Mustapha Stambouli of \\ Mascara, Mascara 29000, Algeria; benhanifia@gmail.com \\ * Correspondence: kumazawa@u-shizuoka-ken.ac.jp; Tel.: +81-54-264-5523
}

Citation: Hosoya, T.; Tsuchiya, I.; Ohta, T.; Benhanifia, M.; Kumazawa, S. Composition of Algerian Propolis, Plant Origin, and Its Antiangiogenic Activity In Vitro. Molecules 2021, 26, 6510. https://doi.org/10.3390/ molecules 26216510

Academic Editors: Vassya Bankova and Milena Popova

Received: 29 September 2021

Accepted: 25 October 2021

Published: 28 October 2021

Publisher's Note: MDPI stays neutral with regard to jurisdictional claims in published maps and institutional affiliations.

Copyright: (c) 2021 by the authors. Licensee MDPI, Basel, Switzerland. This article is an open access article distributed under the terms and conditions of the Creative Commons Attribution (CC BY) license (https:// creativecommons.org/licenses/by/ $4.0 /)$.

\begin{abstract}
The antiangiogenic activity of the ethanol extract of propolis collected from different regions in western Algeria was investigated using in vitro human umbilical vein endothelial cells (HUVECs). The ethanol extract with the strongest activity, i.e., Algerian propolis 1 (EEPA1), inhibited the formation of capillary networks in a dose-dependent manner $(6.25-50 \mu \mathrm{g} / \mathrm{mL})$ within $12 \mathrm{~h}$ and induced cell fragmentation of HUVECs at $50 \mu \mathrm{g} / \mathrm{mL}$ after treatment for $24 \mathrm{~h}$. To identify the active compounds in EEAP1, a high-performance liquid chromatography (HPLC) analysis was performed, revealing that EEAP1 contains two major compounds. Both compounds were isolated by repeated column chromatography and identified as $\omega$-hydroxyferulenol (1) and ferulenol (2), which have a coumarin structure conjugated with a farnesyl group according to NMR, high-resolution electrospray ionization mass spectroscopy, and chemical modification. Compounds $\mathbf{1}$ and $\mathbf{2}$ inhibited the tubeforming activity of HUVECs, especially 2, which exhibited a stronger antiangiogenic effect even at a low concentration of $3.31 \mu \mathrm{g} / \mathrm{mL}$. Moreover, 2 suppressed the elongation and induced cell fragmentation at the same dose. The molecular changes in tube-forming HUVECs induced by 2 were found to be related to the activation of the caspase signals. To confirm the plant origin of propolis, an HPLC comparative analysis of the ethanol extracts of some plants near beekeeping areas and that of Algerian propolis (EEAP1) was performed, and similar chromatographic patterns were observed. This result suggests that the plant origin of this Algerian propolis is the resin of Ferula communis.
\end{abstract}

Keywords: propolis; antiangiogenic; ferulenol; plant origin; Algeria

\section{Introduction}

Propolis is a yellow-green to dark brown resinous hive product that is collected and processed by honeybees from plant buds, exudates, and other botanical sources. It is believed to serve as a protective barrier for the beehive. The main constituents of propolis are beeswax and plant resins. Bees collect these substances on their hind legs and carry them to the hive to seal holes and build structures. It has been also recognized since ancient times that propolis protects the hive against pathogenic microorganisms [1-3], which is an essential characteristic of propolis. Hence, propolis has been used as a traditional folk medicine worldwide [4-6] because of its antioxidant [7,8], antibacterial [9,10], antiinflammatory [11,12], and anticancer activities [13,14]. Accordingly, propolis has gained popularity as an alternative medicine for the prevention and treatment of inflammation, diabetes, heart disease, and cancer [8,14,15].

Studies on the chemical composition of propolis have demonstrated its compositional variability, which largely depends on the source plant(s) [16,17]. The most extended type worldwide is poplar-type propolis derived from poplar buds [18]. However, green propolis, 
which stems from the buds of Baccharis dracunculifolia DC, is the most common type in the southeastern area of Brazil [19] and red propolis, derived from Dalbergia ecastaphyllum (L.) Taub., is collected in the northeastern part of Brazil [20,21]. The source plants of various propolis have been identified by combining bee behavior observation and chemical analysis of both plant resins and propolis. This has allowed for the identification of source plants in Okinawa, Japan (Macaranga tanarius (L.) Müll. Arg.), and in Jeju Island, Korea (Angelica keiskei Ito) [22,23]. Nevertheless, other types of propolis worldwide likely remain undiscovered.

The chemical composition of propolis is qualitatively and quantitatively variable depending on the vegetation in the area from which it is collected [16,18,24]. For instance, poplar-type propolis contains typical poplar bud phenolics such as flavonoid aglycones and phenolic acids (and their esters) [16,18]. By contrast, the main compounds found in Brazilian green propolis are prenylated derivatives of $p$-coumaric acid, diterpenes, lignans, and flavonoids [16].

Our main goals were to discover a new type of propolis and to clarify its biological activity. This study describes the components and biological activity, particularly the antiangiogenic activity, of propolis samples collected from different locations in western Algeria. Although several pharmaceutical studies on the antioxidant, antimicrobial, and anticancer activities of Algerian propolis have been conducted [25-27], to the best of our knowledge, the antiangiogenic activity of Algerian propolis has not been reported yet. In our previous paper, on the basis of in vitro and in vivo angiogenesis models, we reported that Brazilian and Okinawan propolis possess antiangiogenic activities $[13,28]$. Angiogenesis is defined as the process of the formation of new blood vessels from preexisting ones and antiangiogenic activity may be useful in the treatment and prevention of cancer progression $[29,30]$. In this study, we report the chemical analysis, antiangiogenic activity in vitro, and probable botanical source of Algerian propolis.

\section{Results}

\subsection{Investigation of the Anti-Tube-Forming Activity of Algerian Propolis}

The antiangiogenic effect of the ethanol extract of four kinds of propolis (EEAP1, EEAP2, EEAP3, and EEAP4) collected in different locations of western Algeria (Table 1) was investigated by performing a tube formation assay in vitro. As shown in Figure 1, EEAP1 had the strongest antiangiogenic activity, completely inhibiting tube formation and inducing cell fragmentation, which is a morphological hallmark of apoptosis, of human umbilical vein endothelial cells (HUVECs) at $50 \mu \mathrm{g} / \mathrm{mL}$ after $12 \mathrm{~h}$ of treatment. To investigate the antiangiogenic activity of EEAP1 in detail, tube-forming HUVECs were treated with several doses of EEPA1 for 12 and $24 \mathrm{~h}$. Treatment with EEAP1 at $50 \mu \mathrm{g} / \mathrm{mL}$ inhibited the elongation of HUVECs and the formation of capillary networks after $12 \mathrm{~h}$. Furthermore, EEAP1 treatment for $24 \mathrm{~h}$ inhibited the formation of capillary networks in a dose-dependent manner and EEAP1 at $50 \mu \mathrm{g} / \mathrm{mL}$ induced cell fragmentation of HUVECs (Figure 2).

Table 1. Collection areas and properties of the collected propolis samples.

\begin{tabular}{cccc}
\hline Sample No. & Voucher Specimen & Area & Color and Texture \\
\hline 1 & TIA-1 & Tiaret & Dark brown and rigid \\
2 & TIA-2 & Tiaret & Dark brown and rigid \\
3 & NED-TL & Tlemcen & Dark brown and waxy \\
4 & SFS-SBA & Sidi bel Abbés & Brown, waxy, and sticky \\
\hline
\end{tabular}




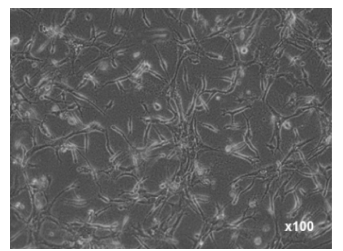

Control (non treated HUVECs)

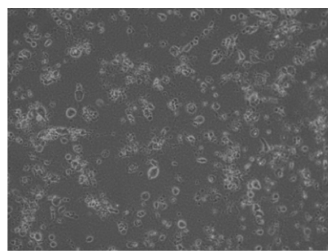

Algerian propolis 1 (EEAP1)

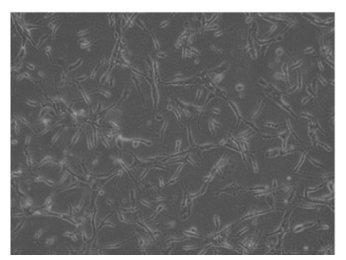

Algerian propolis 3 (EEAP3)

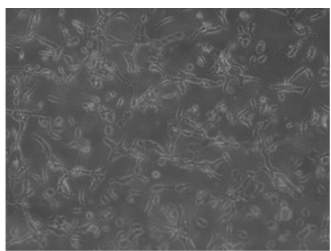

Algerian propolis 2 (EEAP2)

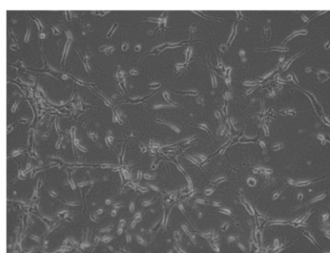

Algerian propolis 4 (EEAP4)

Figure 1. Inhibitory effects of ethanol extracts of Algerian propolis 1-4 (EEAP1-4) on the tube formation of HUVECs. The cells were treated with $50 \mu \mathrm{g} / \mathrm{mL}$ of EEAPs and observed after $12 \mathrm{~h}$. EEAP1 showed the strongest antiangiogenic activity, completely inhibiting the formation of capillary networks and inducing cell fragmentation.
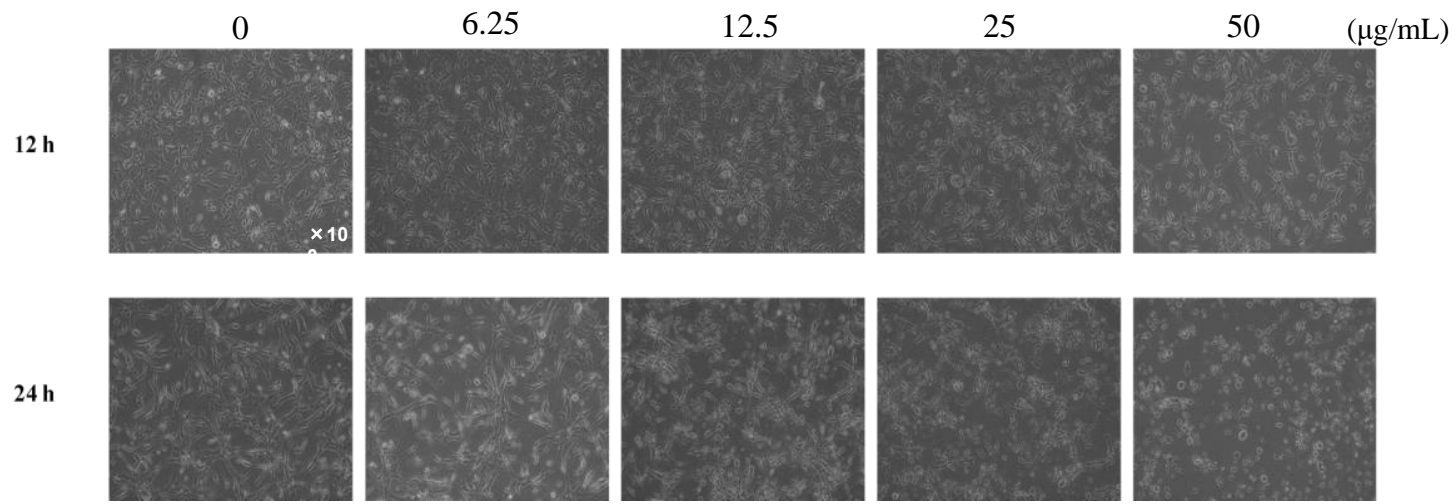

Figure 2. Inhibitory effects of ethanol extracts of EEAP1 on the tube formation of HUVECs. EEAP1 at $50 \mu \mathrm{g} / \mathrm{mL}$ inhibited the elongation of HUVECs and the formation of capillary networks after $12 \mathrm{~h}$. After $24 \mathrm{~h}$ treatment, EEAP1 dose-dependently inhibited the formation of capillary networks.

\subsection{Identification of the Main Compounds in EEAP1}

To identify the compounds responsible for the antiangiogenic activity in EEAP1, a highperformance liquid chromatography (HPLC) analysis was performed, which revealed the presence of two main compounds, as shown in Figure 3. Column chromatography and preparative HPLC (see the Experimental Section for details) led to the isolation of two compounds (1 and 2). However, the HPLC chromatograms of the isolated compounds $\mathbf{1}$ and 2 showed two peaks each. Assuming that the isolated compounds might form two derivatives in hydrogen donor solvents, methylation with trimethylsilyldiazomethane $\left(\mathrm{TMSCHN}_{2}\right.$ ) was performed on the crude fraction before the isolation procedure and the structures of $\mathbf{1}$ and $\mathbf{2}$ were determined using their methyl derivatives. The methylated fraction was subjected to preparative HPLC to provide four peaks with retention times of $14.5,15.8,24.8$, and $27.0 \mathrm{~min}$, which were assigned as compounds $3, \mathbf{5}, \mathbf{4}$, and $\mathbf{6}$, respectively. These compounds were analyzed via high-resolution electrospray ionization mass spectroscopy (HR-ESIMS) as well as via one-dimensional (1D) and two-dimensional (2D) nuclear magnetic resonance (NMR) spectroscopy. 


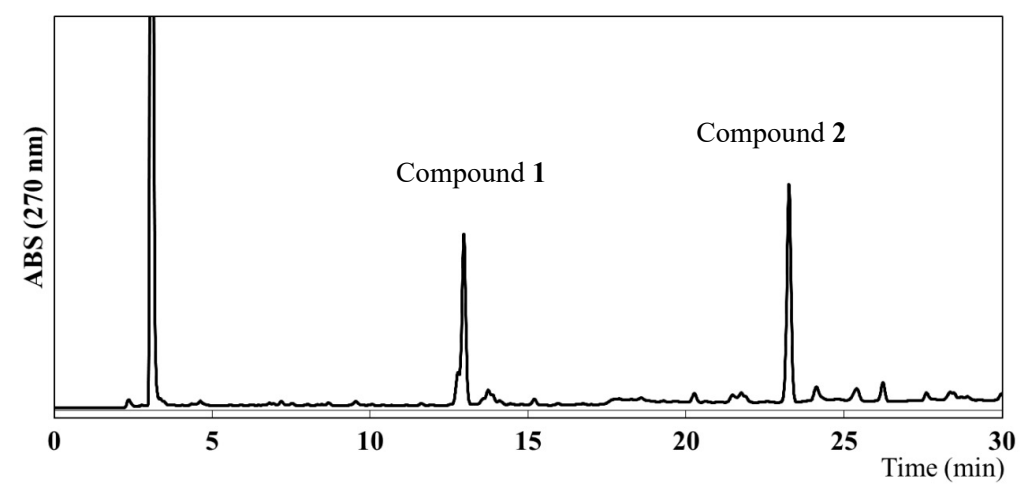

Figure 3. HPLC chromatogram of the ethanol extract of Algerian propolis 1 (EEAP1).

Compound 3 was obtained as an amorphous solid and its molecular formula was determined to be $\mathrm{C}_{25} \mathrm{H}_{32} \mathrm{O}_{4}$ by HR-ESIMS $\left(m / z 419.2194[\mathrm{M}+\mathrm{Na}]^{+}\right.$calculated for $\mathrm{C}_{25} \mathrm{H}_{32} \mathrm{O}_{4} \mathrm{Na}$, 419.2198; Figure S3). The ${ }^{1} \mathrm{H}$ NMR spectrum of 3 in acetone- $d_{6}$ showed signals corresponding to aromatic protons ( $\delta 7.50-8.00)$, a methoxyl group $(\delta 4.06)$, and three methyl groups ( $\delta$ 1.50-1.70; Figure $S 4)$. The ${ }^{13} \mathrm{C}$ NMR spectrum showed 25 signals attributable to a methoxy group ( $\delta 62.4)$, aromatic or olefinic carbons ( $\delta 102.4-136.4)$, two aromatic/olefinic carbons conjugated with a hydroxyl group ( $\delta 153.5$ and 163.4$)$, and a carbonyl carbon ( $\delta 163.9$; Figure S5). The 2D NMR spectra of 3 revealed the presence of a coumarin structure conjugated with a farnesyl group (Figures S6 and S7). Hence, a correlation between methoxyl protons $(\delta 4.06)$ and an aromatic carbon conjugated with a hydroxyl group ( $\delta$ 163.4) indicated the presence of an enol in the coumarin moiety. Consequently, 3 was confirmed to be the enol form of methylated $\omega$-hydroxyferulenol (Figure 4).<smiles>[R7]C(C)=CCCC(C)=CCCC(C)=CCc1c([R7])c2ccccc2oc1=O</smiles>

$\mathrm{R}^{1}$

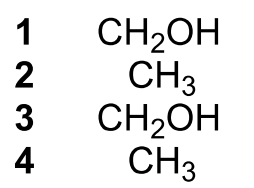

$\mathrm{H}$

$\mathrm{H}$

$\mathrm{CH}_{3}$
$\mathrm{R}^{2}$

$\mathrm{CH}_{3}$<smiles>[R]C(C)=CCC/C(C)=C/CC/C(C)=C/Cc1c(OC)oc2ccccc2c1=O</smiles>

$\mathrm{R}$

Figure 4. Chemical structures of $\mathbf{1}$ ( $\omega$-hydroxyferulenol), 2 (ferulenol), and their methylated compounds (3-6).

Compound 5 was obtained as an amorphous solid with the molecular formula $\mathrm{C}_{25} \mathrm{H}_{32} \mathrm{O}_{4}\left(\mathrm{~m} / z\right.$ 397.2375 [M+H] ${ }^{+}$calculated for $\mathrm{C}_{25} \mathrm{H}_{33} \mathrm{O}_{4}, 297.2379$; Figure S8) according to an HR-ESIMS analysis, which is consistent with that of $\mathbf{3}$. The ${ }^{1} \mathrm{H}$ NMR spectrum of 5 (Figure S9) was also similar to that of 3; however, the ${ }^{13} \mathrm{C}$ NMR spectra of both compounds differed in the low magnetic field region. Specifically, the chemical shift at $\delta 163.4$ in the ${ }^{13} \mathrm{C}$ NMR spectrum of 3 shifted to $\delta 177.4$ in the corresponding spectrum of 5 (Figure S10), which suggests the presence of a ketone in the latter compound and reveals the occurrence of a keto-enol tautomerization between both compounds, as shown in Figure 4 . Accordingly, compound 5 was determined to be methylated $\omega$-hydroxyferulenol containing a keto moiety in the coumarin skeleton (Figure 4 ).

Compounds 4 and 6 were obtained as amorphous solids and their molecular formula was determined to be $\mathrm{C}_{25} \mathrm{H}_{32} \mathrm{O}_{4}$ via HR-ESIMS (4, $\mathrm{m} / z 403.2253$ [M+Na] ${ }^{+}$calculated for $\mathrm{C}_{25} \mathrm{H}_{32} \mathrm{O}_{3} \mathrm{Na}$, 403.2249, and 6, $\mathrm{m} / z$ 381.2431 $[\mathrm{M}+\mathrm{H}]^{+}$calculated for $\mathrm{C}_{25} \mathrm{H}_{33} \mathrm{O}_{3}, 381.2430$; Figures S11 and S12). The molecular weight of 4 and 6 was 16 units smaller than that of 3 
and 5, which suggests that the former compounds contain one hydroxyl group less than the latter. Hence, $\mathbf{4}$ and $\mathbf{6}$ were determined to be methylated ferulenol (Figure 4 ).

According to the chemical structure analyses, $\mathbf{1}$ and $\mathbf{2}$ formed keto-enol isomers in hydrogen donor solvents. Therefore, to avoid isomerization, the isolation and purification of these compounds were performed using aprotic solvents such as hexane, chloroform, and ethyl acetate. As mentioned in the Experimental Section, $\mathbf{1}$ and $\mathbf{2}$ afforded a single peak upon column chromatography and preparative HPLC purification, and were identified as $\omega$-hydroxyferulenol (1) and ferulenol (2), respectively (Figure 4), on the basis of the comparison of their 1D NMR spectroscopy and HR-ESIMS analysis (Figures S1 and S2) with literature data [31].

\subsection{Anti-Tube-Forming Activity of $\omega$-Hydroxyferulenol (1) and Ferulenol (2)}

The effect of the isolated compounds $\omega$-hydroxyferulenol (1) and ferulenol (2) on the angiogenesis of HUVECs was examined in vitro by performing a tube formation assay. HUVECs were treated with these compounds at concentrations of $3.31,6.25$, and $12.5 \mu \mathrm{g} / \mathrm{mL}$ for 12, 24, and $36 \mathrm{~h}$. After the induction of the tube formation, the control endothelial cells formed a network of capillary-like tubes in the absence of $\mathbf{1}$ and $\mathbf{2}$. Treatment with $\omega$-hydroxyferulenol (1) at $12.5 \mu \mathrm{g} / \mathrm{mL}$ inhibited the formation of capillary networks, suppressing the elongation of HUVECs after $12 \mathrm{~h}$ and inducing cell fragmentation after $24 \mathrm{~h}$ (data not shown). Meanwhile, ferulenol (2) had a stronger antiangiogenic effect on tubeforming HUVECs, suppressing the elongation of HUVECs and inducing cell fragmentation even at a low concentration of $3.13 \mu \mathrm{g} / \mathrm{mL}$ (Figure 5).

$12 \mathrm{~h}$

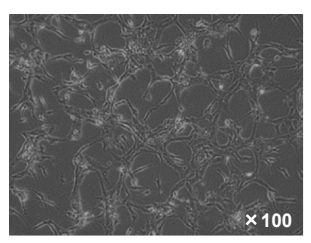

$24 \mathrm{~h}$
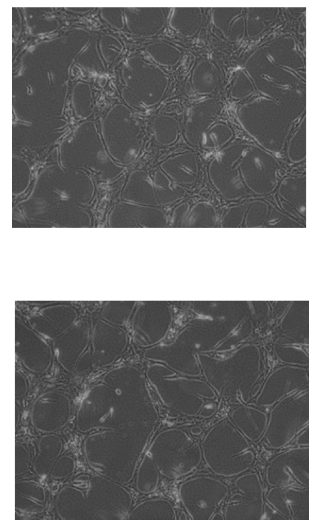

3.13
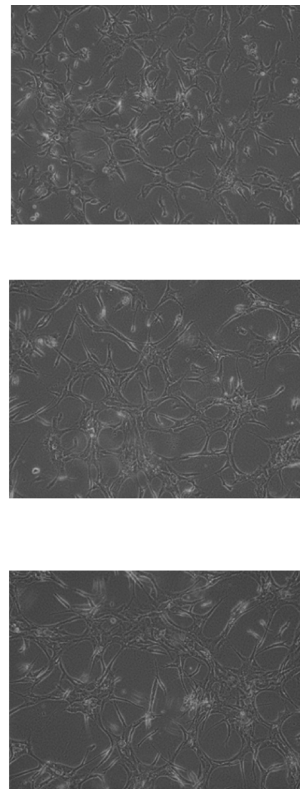

6.25
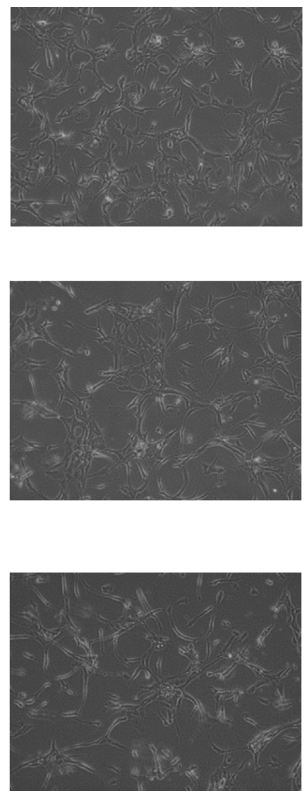

$12.5(\mu \mathrm{g} / \mathrm{mL})$
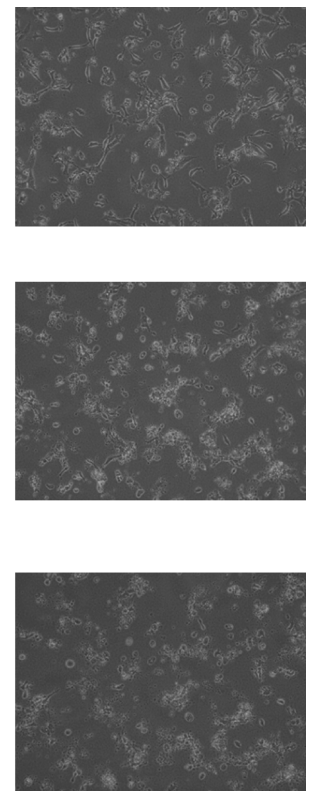

Figure 5. Inhibitory effects of ferulenol (2) on the tube formation of HUVECs. The compound showed a very strong antiangiogenic activity, inhibiting the formation of capillary networks and inducing cell fragmentation dose-dependently even at lower concentrations.

\subsection{Apoptosis Induction of Ferulenol (2)}

As mentioned above, although both compounds $\omega$-hydroxyferulenol (1) and ferulenol (2) inhibited the tube formation of endothelial cells, 2 apparently showed much stronger antiangiogenic activity on HUVECs. To identify the molecular changes in tube-forming HUVECs that led to the cell fragmentation after treatment with ferulenol (2), the activation state of the apoptosis signal caspase-3/7 was analyzed. Treatment of HUVECs with ferulenol (2) at $1.56 \mu \mathrm{g} / \mathrm{mL}$ for $12 \mathrm{~h}$ activated caspase-3. Moreover, cotreatment with 
ferulenol (2) and z-VAD-fmk, which is an inhibitor of caspases, suppressed the caspase-3 activation (Figure 6). These results showed that ferulenol (2) activated the caspase signals, thereby inducing apoptosis and contributing to the inhibition of tube formation.

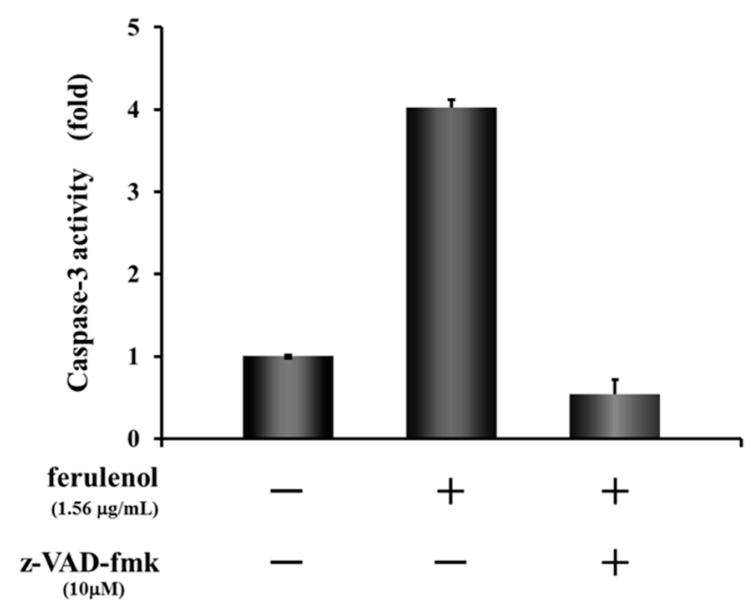

Figure 6. Effect of ferulenol (2) on apoptosis signal.

\subsection{Identification of the Plant Origin of the Studied Propolis}

The ethanol extracts of some of the plants grown around the bee farm in western Algeria, i.e., Inula viscosa, Juniperus phoenicea, and Ferula communis, were investigated using reverse-phase HPLC (RP-HPLC) coupled with HR-ESIMS analysis. As shown in Figure 7, the chromatogram of F. communis was similar to that of EEAP1, which suggests that $F$. communis might be one of the source plants of Algerian propolis. 

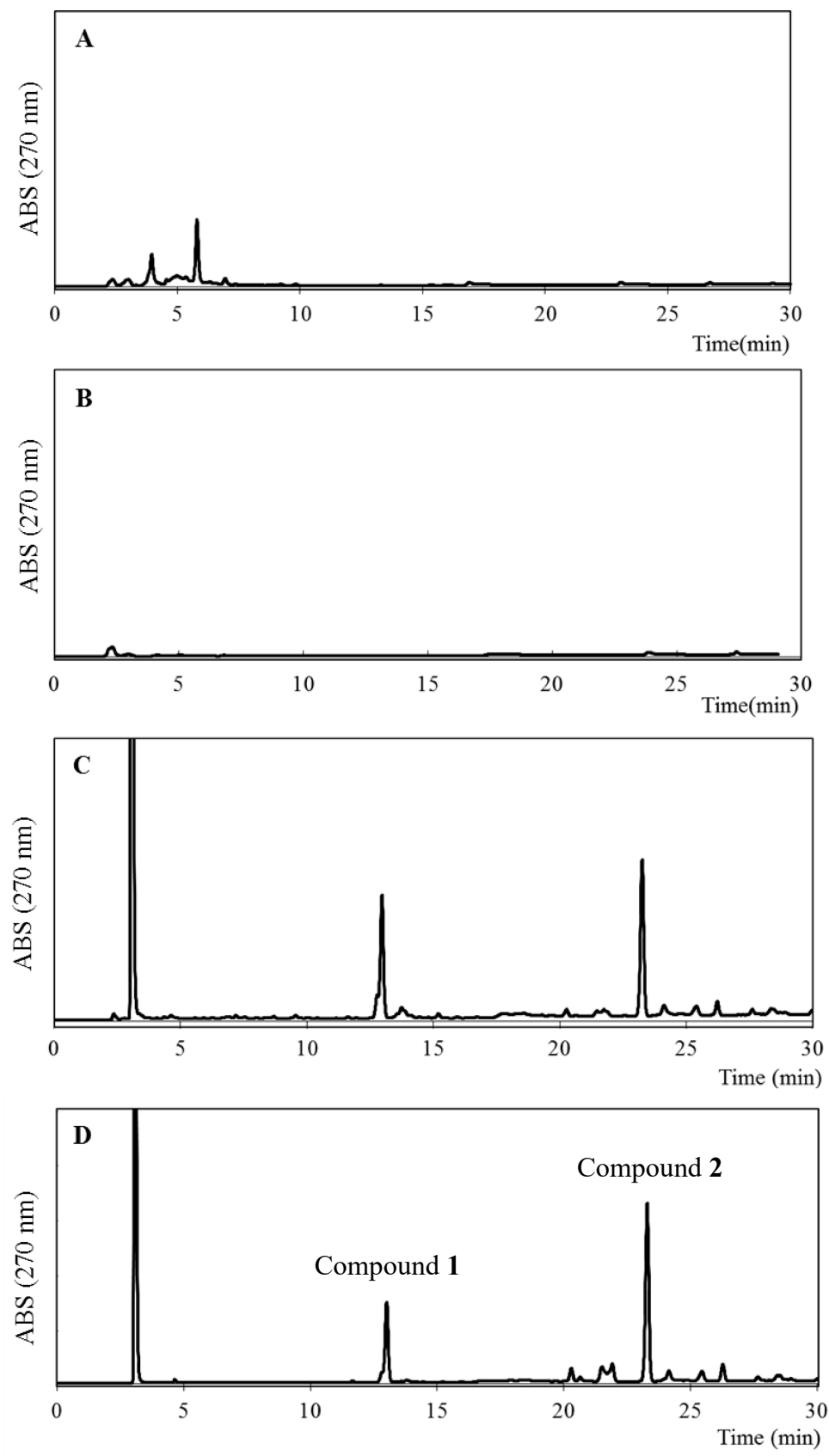

Figure 7. HPLC profiles of ethanol extracts of I. viscosa (A), J. phoenicea (B), F. communis (C), and EEAP1 (D).

\section{Discussion}

Although beekeeping is practiced in Algeria, the byproduct propolis has not been thoroughly studied yet. In this study, to investigate the potential utility of Algerian propolis, its main components were isolated and analyzed, leading to the identification of the active compounds $\mathbf{1}$ and $\mathbf{2}$, whose antiangiogenic activity was examined. Furthermore, the plant origin of the propolis studied was identified.

Compounds 1 and 2 were isolated from EEPA1 and determined to be $\omega$-hydroxyferulenol (1) and ferulenol (2) via NMR and HR-ESIMS analysis. It has been reported that these prenylated coumarins are active components of the latex of Ferula communis [31], which has been identified as the plant origin near the beehive box. Similar to our findings, a previously reported structure-relationship study revealed that ferulenol exhibits stronger antimycobacterial activity than that of hydroxyferulenol [32]. Another study reported that ferulenol shows 
cytotoxicity on liver FAO cells and B16F1 melanoma by inducing proapoptotic effects via a decrease in the mitochondrial membrane potential and mitochondrial respiratory rate [33]. Moreover, Bocca et al. reported the cytotoxic activity of ferulenol against various human tumor cell lines and its mechanism of action, which involves the stimulation of tubulin polymerization and the inhibition of the binding of colchicine to tubulin [34]. As far as we know, reports on the biological activities of $\omega$-hydroxyferulenol and ferulenol are very scarce.

In this biological study, the antiangiogenic effect of $\omega$-hydroxyferulenol (1) and ferulenol (2) on tube formation and cell fragmentation was demonstrated in vitro. Ferulenol (2) exhibited antiangiogenic activity even at a low concentration of $3.13 \mu \mathrm{g} / \mathrm{mL}$. These results suggest that ferulenol (2), which has a prenylated moiety, shows stronger activity at lower concentrations when compared with the hydroxy-prenylated compound $\omega$-hydroxyferulenol (1).

The molecular changes in fragmented HUVECs after treatment with ferulenol (2) were examined and the activation of caspase- 3 at the end of the apoptotic signal was confirmed. Treatment with ferulenol (2) at $1.56 \mu \mathrm{g} / \mathrm{mL}$ for $12 \mathrm{~h}$ activated caspase- 3 and this activation was suppressed by adding the inhibitor z-VAD-fmk. Hence, the caspase activation experiments revealed that cell fragmentation was associated with apoptosis. These results indicate that induction of apoptosis is a critical mechanism of angiogenesis suppression by ferulenol (2). Although we were able to show that ferulenol (2) exhibited antiangiogenesis by inhibiting tube formation and inducing apoptosis in HUVECs in vitro, it remains to be seen whether such activity can also be observed in vivo. Nonetheless, this is the first report demonstrating the antiangiogenic activity of ferulenol on HUVECs, which proceeds via induction of apoptosis by inhibiting the caspase signals. Thus, Algerian propolis may have future applications in the prevention and treatment of angiogenesisrelated diseases.

\section{Materials and Methods}

\subsection{Materials and Chemicals}

Medium 199, medium MCDB-104, and fetal bovine serum (FBS) were purchased from Sigma (St. Louis, MO, USA), Nihon Pharmaceutical (Tokyo, Japan), and Moregate (Brisbane, Australia), respectively. Cellgen was obtained from Koken (Tokyo, Japan). The epidermal growth factor (EGF) and human basic fibroblast growth factor (FGF; recombinant) were purchased from BD Biosciences (Bedford, MA, USA) and the Wako Pure Chemical Corporation (Osaka, Japan), respectively.

\subsection{Equipment for the Isolation and Structure Analysis}

One-dimensional $\left({ }^{1} \mathrm{H}\right.$ and $\left.{ }^{13} \mathrm{C}\right)$ and two-dimensional NMR spectra were measured on a Bruker AVANCE III 400 instrument (Bruker BioSpin, Billerica, MA, USA). Chemical shifts $(\delta)$ were reported in parts per million and coupling constants $(J)$ were reported in hertz. The chemical shifts in the ${ }^{1} \mathrm{H}$ and ${ }^{13} \mathrm{C}$ NMR spectra were corrected using the residual solvent signals. HR-ESIMS was performed using an Accela LC system (Thermo Fisher Scientific, Waltham, MA, USA) equipped with a quadrupole mass spectrometer (Q-Exactive; Thermo Fisher Scientific). RP-HPLC analyses were conducted using a PU-2086 Plus intelligent prep pump (Jasco Co., Inc., Tokyo, Japan) with the UV-970 UV/VIS detector (Jasco Co., Inc.), a Shiseido Capcell Pak C18 UG120 $(4.6 \times 250 \mathrm{~mm})$ column for analysis, and a Shiseido Capcell Pak C18 U120 $(20 \times 250 \mathrm{~mm})$ column for preparative purposes. Preparative normal-phase HPLC was performed using the same pump and detector with a Nomura Chemical (Aichi, Japan) Develosil 60-5 (7.5 × $250 \mathrm{~mm})$ column.

\subsection{Propolis Samples}

Propolis samples were collected from beehives located at different regions in western Algeria, i.e., Tiaret (Samples 1 and 2), Tlemcen (Sample 3), and Sidi bel Abbés (Sample 4), in March-May 2010. Additionally, the sampling collection was conducted under controlled conditions (temperature, light, etc.), and professional beekeepers who did not use any 
antibiotics or other chemicals for treating the beehives were selected. Samples were stored at $-20{ }^{\circ} \mathrm{C}$ in our laboratory.

\subsection{Screening of the Four Algerian Propolis Samples and Isolation of Active Compounds (1 and 2)}

The four propolis samples collected in Algeria were dried and extracted with ethanol at room temperature for $24 \mathrm{~h}$ with stirring. After the evaporation of ethanol, the extract was dissolved in dimethylsulfoxide to investigate the inhibition activity of tube formation at a concentration of $50 \mu \mathrm{g} / \mathrm{mL}$.

Algerian propolis (Sample 1; $10.18 \mathrm{~g}$ ), which showed the strongest activity for the inhibition of tube formation, was extracted with $500 \mathrm{~mL}$ of ethanol for $24 \mathrm{~h}$ with stirring and the subsequent evaporation of ethanol afforded EEAP1. The EEAP1 extract (9.85 g) was dissolved in hexane, placed on top of a silica gel column $(600 \times 45 \mathrm{~mm}$, i.d. $)$, and eluted with a gradient of $n$-hexane/EtOAc and $\mathrm{MeOH}$ to produce 11 fractions. After the elution profile analysis, Fr. 4 contained the main compounds of the propolis.

After silica gel column chromatography, Fr. 4 (128.8 $\mathrm{mg})$ of EEAP1 was dissolved in $0.5 \mathrm{~mL}$ of acetone and $1 \mathrm{~mL}$ of TMSCHN $\mathrm{TM}_{2}$ was added. After incubation at room temperature for $15 \mathrm{~h}$, the solvent was evaporated to afford methylated Fr. 4 (147.2 mg), which was then subjected to RP-HPLC by eluting with a mobile phase composed of $32 \%(v / v)$ acetonitrile in $\mathrm{H}_{2} \mathrm{O}$ containing $0.1 \%$ trifluoroacetic acid to produce $3(3.1 \mathrm{mg}), 4(1.9 \mathrm{mg}), 5(4.6 \mathrm{mg})$, and 6 (2.6 $\mathrm{mg})$.

Apart from methylation, Fr. $4(111 \mathrm{mg})$ was further chromatographed using a silica gel column $(600 \times 25 \mathrm{~mm}$, i.d. $)$ and eluted with a gradient of $n$-hexane/chloroform and acetone. Then, Frs. 4-4 and 4-5 were subjected to normal-phase HPLC and eluted for 60 min with a mobile phase composed of a gradient system of hexane and ethyl acetate (100:0-0:100) to produce pure compounds 1 ( $2.7 \mathrm{mg})$ and 2 (3.2 $\mathrm{mg})$.

\subsection{Cell Culture}

HUVECs were isolated from the human umbilical cord and cultured in a HUVEC growth medium (MCDB-104 medium supplemented with 10\% FBS, $10 \mathrm{ng} / \mathrm{mL}$ of EGF, $100 \mu \mathrm{g} / \mathrm{mL}$ of heparin, and $100 \mathrm{ng} / \mathrm{mL}$ of the endothelial growth factor). Incubation was conducted at $37{ }^{\circ} \mathrm{C}$ under a humidified 95\%/5\% (v/v) mixture of air and $\mathrm{CO}_{2}$. The cells were seeded on plates coated with $0.1 \%$ gelatin and allowed to grow to sub-confluence before experimental treatment.

\subsection{Tube Formation Assay}

Capillary tube-like structures formed by HUVECs in collagen gel were prepared following a previously described procedure with slight modifications [21]. Collagen gels were made using Cellgen (type I collagen). Collagen solution $(200 \mu \mathrm{L}, 0.21 \%$ in Medium199) was poured into the wells of a 24 -well plate and the plates were incubated at $37^{\circ} \mathrm{C}$ for 30 min to solidify the gels. HUVECs $\left(6.0 \times 10^{4}\right.$ cells $\left./ \mathrm{cm}^{2}\right)$ in MCDB-104 medium with $0.5 \%$ FBS were seeded onto the collagen-coated wells and left at $37{ }^{\circ} \mathrm{C}$ under $5 \% \mathrm{CO}_{2}$ in an incubator for $1 \mathrm{~h}$ to allow them to attach to the collagen gel. After removing the medium, $150 \mu \mathrm{L}$ of the collagen solution was overlaid and subjected to gelation as described above. Subsequently, $650 \mu \mathrm{L}$ of MCDB-104 with $0.5 \%$ FBS supplemented with $10 \mathrm{ng} / \mathrm{mL} \mathrm{bFGF}$, $8 \mathrm{nM} / \mathrm{mL}$ of PMA (Phorbol 12-myristate 13-acetate), and various concentrations of samples were added to the wells and incubated for up to $36 \mathrm{~h}$. The resulting web-like capillary structure was observed under a microscope with 100X magnification and captured with an Olympus C-4040ZOOM digital camera (Olympus Co., Tokyo, Japan).

\subsection{Caspase-Glo 3/7 Assay}

HUVECs $\left(5.0 \times 10^{5}\right.$ cells/well $)$ in MCDB-104 medium were seeded onto collagencoated 96-well white-plate wells and left at $37{ }^{\circ} \mathrm{C}$ under $5 \% \mathrm{CO}_{2}$ in an incubator for $1 \mathrm{~h}$ to allow them to attach to the collagen gel. After removing the medium, $100 \mu \mathrm{L}$ of MCDB-104 with 0.5\% FBS supplemented with $10 \mathrm{ng} / \mathrm{mL}$ bFGF, $8 \mathrm{nM} / \mathrm{mL}$ of PMA (Phorbol 
12-myristate 13-acetate), and $3.31 \mu \mathrm{g} / \mathrm{mL}$ of ferulenol (2) with/without z-VAD-fmk was added to the wells and incubated for up to $12 \mathrm{~h}$. After incubation, $80 \mu \mathrm{L}$ of the medium was removed and $20 \mu \mathrm{L}$ of Caspase-Glo 3/7 assay solution was both added and incubated for $1 \mathrm{~h}$ at room temperature. The chemiluminescence was recorded using Soft Max Pro.

\title{
4.8. Sampling of the Resin of Ferula Communis
}

The resin of Ferula communis, grown naturally near an apiary, was collected from the Sfisef province of Sidi bel Abbés, located in western Algeria $\left(35^{\circ} 14^{\prime} \mathrm{N} / 0^{\circ} 14^{\prime} \mathrm{W}\right)$, in September 2012.

\subsection{Statistical Analysis}

Experimental values are expressed as the mean of triplicate experiments \pm standard deviation.

\section{Conclusions}

In this study, the antiangiogenic activity of the ethanol extract of four propolis samples (Samples 1-4) collected in western Algeria was investigated. To identify the active components in the ethanol extract exhibiting the strongest activity (EEAP1), repeated column chromatography and preparative HPLC were performed, which allowed for identifying the major active components as $\omega$-hydroxyferulenol (1) and ferulenol (2). These compounds exhibited an antiangiogenesis effect in vitro on tube-forming HUVECs. Additionally, the plant origin of the studied propolis was determined to be most likely the resin of F. communis on the basis of a comparative analysis. This result indicates that Algerian propolis may have future applications in the prevention and treatment of angiogenesis-related diseases.

Supplementary Materials: The following are available online, Figure S1. HR-ESIMS spectrum of 1, Figure S2. HR-ESIMS spectrum of 2, Figure S3. HR-ESIMS spectrum of 3; Figure S4. 1H NMR spectrum of 3 (400 MHz, acetone-d6); Figure S5. 13C NMR spectrum of 3 (100 MHz, acetone-d6); Figure S6. HSQC spectrum of 3 (acetone-d6); Figure S7. HMBC spectrum of 3 (acetone-d6); Figure S8. HR-ESIMS spectrum of 5; Figure S9. 1H NMR spectrum of 5 (400 MHz, acetone-d6); Figure S10. 13C NMR spectrum of 5 (100 MHz, acetone-d6); Figure S11. HR-ESIMS spectrum of 4; Figure S12. HR-ESIMS spectrum of 6.

Author Contributions: T.H., I.T., and T.O.: investigation and writing—original draft preparation; M.B.: sample collection; S.K.: writing-review and editing, project administration, and supervision. All authors have read and agreed to the published version of the manuscript.

Funding: This research study was funded by JSPS KAKENHI 15K07436 and 18KK0165.

Institutional Review Board Statement: Not applicable.

Informed Consent Statement: Not applicable.

Data Availability Statement: The data presented in this study are available upon request from the corresponding author.

Conflicts of Interest: The authors declare no conflict of interest.

Sample Availability: Samples are available from the authors upon reasonable request.

\author{
Abbreviations \\ EEAP ethanol extracts of Algerian propolis \\ HPLC high-performance liquid chromatography \\ HUVECs human umbilical vein endothelial cells \\ NMR nuclear magnetic resonance \\ HR-ESIMS high-resolution electrospray ionization mass spectroscopy \\ TMS trimethylsilyl
}




\section{References}

1. Ghisalberti, E.L. Propolis: A review. Bee World 1979, 60, 59-84. [CrossRef]

2. Bankova, V.S.; de Castro, S.L.; Marcucci, M.C. Propolis: Recent advances in chemistry and plant origin. Apidologie 2000, 31 , 3-15. [CrossRef]

3. Bankova, V. Chemical diversity of propolis makes it a valuable source of new biological active compounds. J. ApiProd. ApiMed. Sci. 2009, 1, 23-28. [CrossRef]

4. Sforcin, J.M.; Bankova, V. Propolis: Is there a potential for the development of new drugs? J. Ethnopharmacol. 2011, 133, 253-260. [CrossRef]

5. Sforcin, J.M. Biological properties and therapeutic applications of propolis. Phytother. Res. 2016, 30, 894-905. [CrossRef]

6. Oryan, A.; Alemzadeh, E.; Moshiri, A. Potential role of propolis in wound healing: Biological properties and therapeutic activities. Biomed. Pharmacother. 2018, 98, 469-483. [CrossRef]

7. Hamasaka, T.; Kumazawa, S.; Fujimoto, T.; Nakayama, T. Antioxidant activity and constituents of propolis collected in various areas of Japan. Food Sci. Technol. Res. 2004, 10, 86-92. [CrossRef]

8. Kocot, J.; Kiełczykowska, M.; Luchowska-Kocot, D.; Kurzepa, J.; Musik, I. Antioxidant potential of propolis, bee pollen, and royal jelly: Possible medical application. Oxid. Med. Cell. Longev. 2018, 2018, 7074209. [CrossRef]

9. Inui, S.; Hosoya, T.; Shimamura, Y.; Masuda, S.; Ogawa, T.; Kobayashi, H.; Shirafuji, K.; Moli, R.T.; Kozone, I.; Shin-ya, K.; et al. Solophenols B-D and solomonin: New prenylated polyphenols isolated from propolis collected from the Solomon Islands and their antibacterial activity. J. Agric. Food Chem. 2012, 60, 11765-11770. [CrossRef]

10. Przybyłek, I.; Karpiński, T.M. Antibacterial properties of propolis. Molecules 2019, 24, 2047. [CrossRef] [PubMed]

11. Franchin, M.; Freires, I.A.; Lazarini, J.G.; Nani, B.D.; da Cunha, M.G.; Colón, D.F.; de Alencar, S.M.; Rosalen, P.L. The use of Brazilian propolis for discovery and development of novel anti-inflammatory drugs. Eur. J. Med. Chem. 2018, 153, 49-55. [CrossRef] [PubMed]

12. Inui, S.; Hosoya, T.; Yoshizumi, K.; Sato, H.; Kumazawa, S. Phytochemical and anti-inflammatory properties of Senegalease propolis. Fitoterapia 2021, 151, 104861. [CrossRef]

13. Ahn, M.R.; Kunimasa, K.; Ohta, T.; Kumazawa, S.; Kamihira, M.; Kaji, K.; Uto, Y.; Hori, H.; Nagasawa, H.; Nakayama, T. Suppression of tumor-induced angiogenesis by Brazilian propolis: Major component artepillin $\mathrm{C}$ inhibits in vitro tube formation and endothelial cell proliferation. Cancer Lett. 2007, 252, 235-243. [CrossRef] [PubMed]

14. Sepúlveda, C.; Núñez, O.; Torres, A.; Guzmán, L.; Wehinger, S. Antitumor activity of propolis: Recent advances in cellular perspectives, animal models and possible applications. Food Rev. Int. 2020, 36, 429-455. [CrossRef]

15. Pasupuleti, V.R.; Sammugam, L.; Ramesh, N.; Gan, S.H. Honey, propolis, and royal jelly: A comprehensive review of their biological actions and health benefits. Oxid. Med. Cell. Longev. 2017, 2017, 1259510. [CrossRef]

16. Salatino, A.; Fernandes-Silva, C.C.; Righi, A.A.; Salatino, M.L.F. Propolis research and the chemistry of plant products. Nat. Prod. Rep. 2011, 28, 925-936. [CrossRef] [PubMed]

17. Bankova, V.; Popova, M.; Trusheva, B. The phytochemistry of the honeybee. Phytochemistry 2018, 155, 1-11. [CrossRef]

18. Kumazawa, S.; Hamasaka, T.; Nakayama, T. Antioxidant activity of propolis of various geographic origins. Food Chem. 2004, 84, 329-339. [CrossRef]

19. Kumazawa, S.; Yoneda, M.; Shibata, I.; Kanaeda, J.; Hamasaka, T.; Nakayama, T. Direct evidence for the plant origin of Brazilian propolis by the observation of honeybee behavior and phytochemical analysis. Chem. Pharm. Bull. 2003, 51, 740-742. [CrossRef] [PubMed]

20. Inui, S.; Hatano, A.; Yoshino, M.; Hosoya, T.; Shimamura, Y.; Masuda, S.; Ahn, M.R.; Tazawa, S.; Araki, Y.; Kumazawa, S. Identification of the phenolic compounds contributing to antibacterial activity in ethanol extracts of Brazilian red propolis. Nat. Prod. Res. 2014, 28, 1293-1296. [CrossRef]

21. Ccana-Ccapatinta, G.V.; Mejía, J.A.A.; Tanimoto, M.H.; Groppo, M.; de Carvalho, J.C.A.S.; Bastos, J.K. Dalbergia ecastaphyllum (L.) Taub. and Symphonia globulifera L.f.: The botanical sources of isoflavonoids and benzophenones in Brazilian red propolis. Molecules 2020, 25, 2060. [CrossRef] [PubMed]

22. Kumazawa, S.; Nakamura, J.; Murase, M.; Miyagawa, M.; Ahn, M.-R.; Fukumoto, S. Plant origin of Okinawan propolis: Honeybee behavior observation and phytochemical analysis. Naturwissenschaften 2008, 95, 781-786. [CrossRef] [PubMed]

23. Shimomura, K.; Inui, S.; Sugiyama, Y.; Kurosawa, M.; Nakamura, J.; Choi, S.J.; Ahn, M.-R.; Kumazawa, S. Identification of the plant origin of propolis from Jeju Island, Korea, by observation of honeybee behavior and phytochemical analysis. Biosci. Biotechnol. Biochem. 2012, 76, 2135-2138. [CrossRef] [PubMed]

24. Ahn, M.-R.; Kumazawa, S.; Hamasaka, T.; Bang, K.S.; Nakayama, T. Antioxidant activity and constituents of propolis collected in various areas of Korea. J. Agric. Food Chem. 2004, 52, 7286-7292. [CrossRef]

25. Brihoum, H.; Maiza, M.; Sahali, H.; Boulmeltoiu, M.; Barratt, G.; Benguedouar, L.; Lahouel, M. Dual effect of Algerian propolis on lung cancer: Antitumor and chemopreventive effects involving antioxidant activity. Braz. J. Pharm. Sci. 2018, 54, e17396. [CrossRef]

26. Bedaida, I.K.; Masry, S.H.D.; Mamache, B.; Shehata, M.G.; Benammar, L.; Ayachi, A. Ethanolic extract of Algerian propolis induced cell damage in Staphylococcus aureus: A promising alternative as a natural biopreservative in food products. Acta Aliment. 2020, 49, 505-514. [CrossRef] 
27. Segueni, N.; Keskin, M.; Keskin, Ş.; Kadour, B.; Kolayli, S.; Salah, A. Comparison between phenolic content, antioxidant, and antibacterial activity of Algerian and Turkish propolis. Comb. Chem. High Throughput Screen. 2021, 24, 1679-1687. [CrossRef]

28. Tsuchiya, I.; Hosoya, T.; Ushida, M.; Kunimasa, K.; Ohta, T.; Kumazawa, S. Nymphaeol-A isolated from Okinawan propolis suppresses angiogenesis and induces caspase-dependent apoptosis via inactivation of survival signals. Evid. Based Complementary Alternat. Med. 2013, 2013, 826245. [CrossRef]

29. Gordon, M.S.; Mendelson, D.S.; Kato, G. Tumor angiogenesis and novel antiangiogenic strategies. Int. J. Cancer 2010, 126, 1777-1787. [CrossRef]

30. Abbaszadeh, H.; Keikhaei, B.; Mottaghi, S. A review of molecular mechanisms involved in anticancer and antiangiogenic effects of natural polyphenolic compounds. Phytother. Res. 2019, 33, 2002-2014. [CrossRef]

31. Valle, M.G.; Appendino, G.; Nano, G.M.; Picci, V. Prenylated coumarins and sesquiterpenoids from Ferula communis. Phytochemistry 1986, 26, 253-256. [CrossRef]

32. Appendino, G.; Mercalli, E.; Fuzzati, N.; Arnoldi, L.; Stavri, M.; Gibbons, S.; Ballero, M.; Maxia, A. Antimycobacterial coumarins from the sardinian giant fennel (Ferula communis). J. Nat. Prod. 2004, 67, 2108-2110. [CrossRef] [PubMed]

33. Malika, B.; Amar, Z.; Lamia, B.; Gillian, B.; Mesbah, L. Cytotoxicity of sesquiterpenes ferulenol and coladin on liver FAO and B16F melanoma cells. Pharmacogen. Mag. 2018, 14, 333-337.

34. Bocca, C.; Gabriel, L.; Bozzo, F.; Miglietta, A. Microtubule-interacting activity and cytotoxitity of the prenylated coumarin ferulenol. Planta Med. 2002, 68, 1135-1137. [CrossRef] [PubMed] 